\title{
Clinical Practice of Midwifery Graduates During Community Service Placement, Limpopo Province South Africa
}

\author{
Khathutshelo G. Simane-Netshisaulu ${ }^{1} \&$ Maria S. Maputle ${ }^{1}$ \\ ${ }^{1}$ Department of Advanced Nursing Science, University of Venda, South Africa \\ Correspondence: Khathutshelo G. Simane-Netshisaulu, Department of Advanced Nursing, University of Venda, \\ Private Bag X5050, Thohoyandou 0950, South Africa. Tel: 27-72-692-6926. E-mail: \\ Khathu.Netshisaulu@univen.ac.za
}

Received: June 3, 2019 Accepted: July 8, 2019 Online Published: August 16, 2019

doi:10.5539/gjhs.v11n10p97 URL: https://doi.org/10.5539/gjhs.v11n10p97

\begin{abstract}
Midwifery graduates are placed in health facilities for community service during their first year of practice. The purpose of the study was to explore how midwifery graduates experienced their clinical practice during community service placement in Limpopo province. A qualitative study which is explorative and descriptive in nature was conducted in five selected hospitals. Population comprised of all midwifery graduates who have undergone a comprehensive nursing programme regulated by R425 of 19 February 1985, as amended; working in selected hospitals. Non-probability, purposive sampling method was used to select five graduates working in maternity unit of each selected hospital. Sample comprised of twenty-five participants. In-depth face to face interviews were used to collect data. Findings revealed that graduates experienced differences between theory and practice at different levels. Loss of students' status, high level of responsibility and inadequate clinical learning opportunities made their transition difficult. In conclusion, graduates felt exposed to two different worlds of midwifery practice resulting in frustration and reality shock. Study recommends that midwifery training programme include opportunities to discuss realities of transition period, to enable graduates to deal with midwifery issues in a real and practical situation. Mentors should help graduates to bridge the gap between theory and practice. Structured support programmes should be offered to alley feelings of fear and insecurity resulting from increased levels of responsibility and accountability graduates are faced with.
\end{abstract}

Keywords: clinical practice, community service placement, midwifery graduate, transition period

\section{Introduction}

The health care system demands competent midwifery practitioners to provide quality midwifery services (Stone, 2016). In the light of competency being a national priority and statutory demand, the South African Nursing Council (SANC), prescribed that all newly qualified midwives who have undergone a comprehensive programme (R425 of 19 February 1985, as amended), be placed in public hospitals to complete one year of compulsory community service (Act No. 33, 2005). The main aim of the compulsory placement is that; newly qualified midwives be supported, orientated and mentored as they transit from student status to professional status. On completion of this compulsory placement, the newly graduated midwives become registered as independent practitioners by the South African Nursing Council.

In a study conducted by Kensington, Campbell, Gray, Dixon, Tumilty, Pairman, Calvert and Lennox (2016), it was reported that, the process of transition from being a midwifery student to a professional midwife is very much challenging and stressful; as graduates have their unrealistic expectations which might be far much different from the reality of clinical practice. Wain (2017) echoed the same sentiments when reporting that, on completion of training, graduates are proud and perceive themselves as highly knowledgeable, when faced with the real world of work they suffer frustration when they realise they are unable to cope. According to Cummins, Denney-Wilson and Homer (2016), newly qualified midwives' level of competence was threatened by high level of responsibility and accountability they were faced with, which left them unsecured. Graduates felt they were not capable of performing administrative tasks including supervision of students which impacted negatively on their self-esteem (Cummins et al., 2016). In a study conducted Power (2016), acknowledged the fact that they were unable to cope with the demands of the new role, and therefore, requested that they be supported during their transition period; as there was no structured support programme to facilitate effective transition from being students to professional 
practitioners. Hence, the study conducted by Stone (2018) emphasized the importance of provision of effective support programme to newly qualified midwives which should be in the form of preceptorship programmes.

However, literature shows limited evidence of the studies conducted in Limpopo province regarding clinical practice of midwifery graduates during community service placement. During clinical accompaniment of midwifery students in hospitals of Limpopo, the researcher interacted with some of the newly graduated midwives who qualified from a comprehensive programme, and were placed in maternity units for compulsory community service. On observation, the researcher noticed that it was common to find midwifery graduates being in charge of shifts when all senior members were off duty. At certain instances, graduates were left to deliver patients alone without any support from experienced midwives. It was in this light that the researcher conducted the study to explore the experiences of midwifery graduates regarding their clinical practice during community service in Limpopo province, South Africa.

\section{Material Studied, Area Descriptions, Methods and Techniques}

\subsection{Material Studied and Area Descriptions}

\subsubsection{Objective}

The objective of the study was to explore how midwifery graduates experienced their clinical practice during community service placement in Limpopo province.

Theoretical Framework

The article was conceptualized within the transition theory. The transition theory was critical in this study because it helped in understanding how midwifery graduates experienced clinical practice during community service which was their journey of becoming professional practitioners. The point of departure in transition theory is that the process of transition to professional practice among midwifery graduates evolves in a fairly predictable manner organised in three stages: doing, being and knowing (Duchscher, 2009).

The Stage of Doing

This is the honeymoon phase, where graduates are excited and exhilarated as they start their journey to professional practice; and lasts for the first 3-4 months (orientation period). The theorist acknowledges that midwifery graduates enter the profession with unrealistic expectations such as being able to function as professionals. It is during this stage whereby, newly graduated midwives are expected to learn how to cope, adapt and adjust themselves to both the new environment and the new role as they have lost their student status to being professional practitioners. Graduates at this stage are anxious and full of uncertainty regarding whether they will be able to meet the responsibilities of a new role or not; and require to be given directions on what to do in particular clinical situations.

The Stage of Being

This is the stage which is characterized by a consistent and rapid advancement in graduates' thinking, knowledge level and skill competency. Unlike in the doing stage, graduates at this stage are able to make sense of their roles and responsibilities as professionals despite the fact that they still experience challenges regarding a lot of uncertainties within the health care system.

The Stage of Knowing

The model is applicable to this study as the newly graduated midwives at this stage are more familiar and comfortable with their professional positions; their relationship with the colleagues is improved. These enable them to explore their professional environment with a critical eye. It is during this time whereby everybody start feeling their impossible way of thinking and doing things as it is the way they have been socialized. The theoretical framework is relevant to this study in the sense that graduates' transition journey occurs in stages. During the initial phase, they are anxious and full of uncertainty regarding whether they will be able to meet the responsibilities of a professional practitioner or not; in the second phase, graduates are able to make sense of their roles and responsibilities as professionals, however, they still experience challenges regarding management of certain activities. Finally, graduated midwives at this stage are more familiar and comfortable with their professional positions and their relationship with the colleagues is improved.

\subsection{Methods and Techniques}

\subsubsection{Instrumentation and Data Collection}

A qualitative study which is explorative and descriptive in nature was conducted in a maternity unit of a selected hospital from each of the five districts of Limpopo province. Population comprised of all newly qualified 
midwives who have undergone a comprehensive nursing programme (R425 of 19 February 1985, as amended) and qualified as nurses (general, psychiatric and community) and midwives working in selected hospitals in Limpopo province. Non-probability, purposive sampling method was used to select five midwifery graduates working in maternity unit of each selected hospital, during their first year following completion of training. Twenty five midwifery graduates constituted a sample. Data were collected using unstructured face-to-face interviews which were conducted until saturation was reached; of which the rationale was to obtain first-hand information and observe non-verbal cues from participants during the interviews. Each session lasted for about 45 to 60 minutes. Interviews were useful to the researcher to understand how midwifery graduates experienced their clinical practice of midwifery services during community service. An open ended question and probes were used to facilitate unrestricted expressions and responses from the participants. Permission to use voice recorder was obtained and recordings were transcribed verbatim. Field notes were documented during interviews and given meaning. Trustworthiness was ensured through credibility, transferability, dependability and confirmability based on Lincoln and Guba's principles as described in De Vos, Strydom, Fouche, Delport (2013). Data from unstructured interviews were analysed qualitatively using Tesch's open coding method which included the following steps: careful reading of all the transcripts by the researcher to get a sense of whole; compilation of a list of similar topics; grouping of data according to themes and sub- themes and coding and categorization of field notes. Literature control was done to contextualise the results of the study (Creswell, 2016).

\subsection{Ethical Considerations}

Ethical clearance (SHS /16/PDC/06/1304), was obtained from the Ethics Committee of the University of Venda; and permission to access the health facilities for conduction of the study was obtained from Department of Health (at Provincial and district levels), as well as managers of selected hospitals. Participants' informed consent was sought, and their participation was voluntary. Participants' identity and personal information was not obtained, to ensure the ethical obligation of confidentiality and privacy of the participants.

\section{Results}

The findings emanated from the interviews conducted with twenty five midwifery graduates practicing in maternity units of the selected hospitals during their first year following their completion of training. Five graduates were from each hospital. Females constituted $94.8 \%$ whereas males were $5.2 \%$. In terms of ethnic groups, $38.8 \%$ were Pedi, 39.1\% Tsongas, $8.7 \%$ Swati and $13.4 \%$ Venda. Of all the participants, $70 \%$ have undergone their training at the universities whereas $30 \%$ undergone their training at the college of nursing. Graduates shared their experiences regarding their clinical practice of midwifery services during community service, which have an impact on the type of midwifery services they provide to patients. Data from participants were consolidated and linked to each other to form clusters; two themes and four sub-themes emerged as presented in Table 1.

Table 1. Themes and sub-themes

\begin{tabular}{ll}
\hline Themes & Sub-themes \\
\hline \multirow{3}{*}{ Different worlds of midwifery practice } & $\begin{array}{l}1.1 \text { Difference between theory and practice experience occurred on } \\
\text { different levels } \\
1.2 \text { Inadequate clinical learning opportunities and experiences during } \\
\text { midwifery practice }\end{array}$ \\
\hline $\begin{array}{l}\text { 2. Reality shock experienced during midwifery } \\
\text { practice }\end{array}$ & 2.1 Loss of student's status \\
& 2.2 High level of responsibility and accountability \\
\hline
\end{tabular}

\subsection{Different Worlds of Midwifery Practice}

The results of the study revealed that midwifery graduates marked the difference between the theoretical midwifery learnt in the classroom and the midwifery practiced in the clinical setting; resulting in frustration during their transition period. Two sub-themes emerged as follows: difference between theory and practice experience occurred on different levels as well as inadequate clinical learning opportunities and experiences during midwifery practice.

\subsubsection{Difference Between Theory and Practice Experience Occurred on Different Levels}

Based on the results, midwifery graduates became frustrated and angry when they realized that most of the skills 
are performed differently from what they learnt during training.

This was confirmed by the following excerpts: 'There is a great difference between the theory I learnt in the classroom and what is really happening here in the ward. It is so frustrating, when you perform procedures methodically; they say you are taking too much time. Some even pass such remarks like 'we are not in the classroom here, where you do things that are not real. Here we do real things because we are dealing with the patients.' That is what they say, and I feel confused.'

A participant corroborated and said: 'When we do procedures they want us to do them in their own way, not in the way we were taught in class. For example in the class we were taught that when we put up a drip we must also write in the fluid chart, when I do that they say, 'you are wasting time as long as the drip is running it is fine (but I argued that I won't stop that since I need to balance the fluid). After all, what we want to have is to give strength to the woman in labour and nothing else.' I feel confused because I don't know why that is done.'

Another participant supported: "Sometimes you are caught in the middle when you realise that what is being done in practice is completely different from what is in the books and what you have been taught in the classroom, especially if the outcome becomes positive in the sense that the patient recovers well and maybe even faster. Frustration becomes worse when you realise that the quick methods they are taking are really working. Oh, how must I do it now?"

Graduates argued that they felt they were competent on performance of midwifery procedures, unfortunately the same procedures were done differently which negatively affected their confidence.

\subsubsection{Inadequate clinical learning opportunities and experiences during midwifery practice}

Based on the findings, graduates were denied the opportunity to learn as the clinical environment was not conducive; which negatively affected their competence and confidence level. A participant stated: 'We were well prepared academically; however, we were supposed to have been mentored especially in areas such as labour ward, perineal suturing and high-risk areas like shoulder dystocia. These are critical areas and we still don 't have enough experience.' Another participant said: 'Some of the procedures that scare me a lot are drug administration and management of complicated deliveries. At least if experienced midwives were committed to guide us, and managers should organise workshops for us'. According to Power (2016), newly qualified midwives suffered frustration which also affected their confidence, as they were not exposed to conducive learning and supportive environment.

\subsection{Reality Shock Experienced During Midwifery Practice}

The findings revealed that newly graduated midwives were excited that they have successfully completed their training. However, on the other hand they were shocked as they were faced with reality that they were expected to function as competent professional practitioners who should take decisions that determine patients' well-being.

\subsubsection{Loss of Student's Status}

Frustration resulting from loss of students' status was evidenced by what the participants said: 'I am shocked as I am faced with reality that I have to stand on my own. I am so miserable because I have lost the status of being a student whereby we were addressed as 'a group of students'. Instead, students are now looking up at me for assistance; patients are demanding quality care and other nurses expect me to work independently. This situation is so stressful.'

Another participant stated: 'The fact that I am a professional nurse is good and makes me happy, but the fact that every junior member of staff looks up at me for solution is stressful and makes me wish somehow I were still in students' boots. It's unlike when I was a student. Being a student is really safe.' This was confirmed: 'Being a professional nurse is good because it is part of growth. You learn to put everything you were taught in practice, be responsible and accountable when delivering care to patients. What is frustrating is that you learn to do all these things, at the same time you also learn to think creatively so that you make reasonable decisions because nobody is supervising you. At this stage I have no one to depend on, unlike when I was still a student where I used to depend on my lecturers and the supervisors. I feel stressed and anxious'. Loss of student status was also described as a cause of concern by graduates who believed did not receive enough structured support from the senior midwives (Wain, 2017).

\subsubsection{High Level of Responsibility and Accountability}

High level of responsibility and accountability accompanying a new role led to frustration, as confirmed in the excerpts: 'One thing that makes me scared is the high level of responsibility and accountability accompanying this new role, whereby I am expected to make decisions regarding care of patients as well as management of the ward. 


\section{Ifeel like I can run away.'}

A participant confirmed: 'I like being a professional nurse, but it's very stressful, everything just has to be perfect. What makes the situation worse is that, you're also expected to be accountable for the actions of the subordinates. Oh! It's such a challenge. I really need strong supervision and support before I can manage that on my own.' Another participant made a confirmation: 'Maybe it would be better if we were given one responsibility at a time. Like for instance, if we were only responsible for patients' care, but it is not like that. They expect us to do everything including teaching and supervision of students, Oh! That's too much. How can I be expected to take care of students when I am still struggling like this?'

According to Delaney (2013), midwifery graduates experienced problems in adjusting themselves with the role of a professional midwife; as they were not certain whether they would be able to carry out the functions of a professional midwife.

\section{Discussion}

Midwifery graduates found it hard to cope with the demands of clinical practice as they felt insecure and frustrated; which resulted from the difference they marked between theory learnt during training and the way skills were performed in the clinical setting. According to Kensington et al. (2016)'s report, newly qualified midwives were concerned about the differences that existed between the knowledge they acquired in the classroom regarding performance of skills and the way procedures are done in the clinical setting; which led to confusion. Power (2016) echoed the same sentiments when reporting that theory practice gap should be addressed as it may lead to a situation whereby graduates may start to question the credibility of the training they have undergone.

In a study conducted by Wain (2017), participants described feeling frustrated, angry and emotionally distressed due to their inability to cope with a new role because the way care was provided to patients was different from how they were trained. This was supported by Power (2017), who reported that the discrepancy between woman-centred care and the management of care provided in the hospital setting confuses the newly graduated midwives and diminishes the midwifery role. Wain (2017) further reported that newly qualified midwives felt they were inadequately prepared for their roles and found it difficult to comprehend why they were educated to be confident and assertive, however, it was not the case in the real clinical situation as they were required to obey orders and conform.

The need for the new graduate to navigate the theory practice gap was also alluded to by Duchscher (2009), who studied the transition process for nurses over a ten-year period in Canada. In her latest work she confirmed the new graduate's experience of "role performance stress, moral distress, discouragement and disillusionment" during the transition period. Whilst appropriate support can assist the new graduate to some extent, Duchscher (2009) argues that this is an inevitable part of transition from student to practitioner, and as such senior students should be prepared within their training for this experience.

Cummins et al. (2016) reported that at the point of registration, participants expressed the belief that their training and experiences of caseload held practice, community, birth centre and hospital focused care provision had prepared them well for their post as a qualified midwife. However, as time since qualification elapsed, they became more sceptical about the preparation they have received. At 4 months post-registration, the newly qualified midwives considered that their training had not fully equipped them for the real world of clinical practice (Hobbs, 2012). In a study conducted in Australia, Power (2015) reported that newly qualified midwives recommended that better preparation should be done during the educational programme so as to address the difference between theory and practice. Some of the issues to be taken note of during students' training are: prioritising and managing care in a busy postnatal unit, care of mothers with mental health problems, antenatal screening and care of a baby with congenital abnormalities (Power, 2015).

Based on the findings, graduates were denied the opportunity to learn as the clinical environment was not conducive; which negatively affected their competence and confidence level. This is contrary to what was reported by Tarimo, Moyo, Masenga, Magesa, and Mzava (2018) that effective and good quality learning environment should be created for newly qualified midwives as a form of support they need during transition period. According to Black (2018), failure to mentor newly qualified midwives is equals to predisposing them to vulnerability, as they may not acquire the competence and skills required to become confident practitioners by the end of transition period.

Graduates felt anxious and frustrated when exposed to perform certain skills all by themselves without mentors as they did not feel confident enough to do so, despite their training. Graduates felt that structured support programme would do justice during their transition process. In a study conducted by Wain (2017), midwifery graduates felt 
that they have good knowledge base around complications and high-risk maternity care, however this knowledge often came from university lectures or skills teaching and simulations, as they did not deal with these events in practice until they were qualified. Power (2017) supported when reporting that, a participant stated that she thought she knew what to do during an emergency, but due to lack of experience, she was a bit slow and felt useless when the mentor came in and took over. Stone (2018) supported what was reported by the previous sources when revealing that, although induction of labour was taught during training, it was not easy for the new graduates to deal with the actual processes and timing of events during a real scenario. Newly qualified midwives also expressed anxiety about preparing a woman for delivery by emergency caesarean section, even when this was mastered in the classroom (Power, 2017).

In a study conducted by Kensington et al. (2016) graduates revealed that, a major cause of anxiety during transition period was drug administration as students carried this procedure out only under rigorous supervision; but were expected to practise unsupervised following qualification. The findings by Cummins et al. (2018) reflected similar version when they noted the inconsistencies in preparation for management, suggesting that while the theoretical context was adequate, the practical aspects, such as drug administration, prioritising, decision making, and clinical skills were variable. The authors further argued that these areas of practice are not adequately addressed during the educational preparation of nurses and midwives (Cummins et al., 2018).

Though midwifery graduates are excited that they have successfully completed their training; they were shocked as they were faced with reality that they were expected to function as competent professional practitioners who should take decisions that determine patients' well-being. This was conversant with what has been reported by Duchscher (2009) that, newly-qualified midwives experienced mixed emotions of satisfaction and sense of achievement; on the other hand, nervous and apprehensive upon qualification. These emotions were also reported by Stone (2016) who revealed that newly-qualified midwives experienced insecurity, nervousness and anxiety as they no longer relied on their preceptors who acted as umbrellas who shielded them during training. In a study conducted by Cummins et al. (2016), the authors echoed similar sentiments when reporting that graduates experienced the positive benefits of being qualified, but also had to deal with related negative impacts, such as a feeling of loss of sheltered academia accompanied by anxiety as a burden.

In their study on 'graduates' experiences regarding transition', Kensington et al. (2016), revealed that participants reported a situation that was challenging to them in terms of lack of experience, heavy workload whereby patients demanded quality care whereas students needed to be supervised. Stone (2018) concurred, when reporting about the reality of busy clinical areas where graduates were expected to be responsible for management of the ward, patient care and supervision of subordinates including students; and all these left participants feeling frustrated. Wain (2017) reported that, despite an obvious lack of support, newly qualified nurses learnt to cope with the change in status from supernumerary student to independent practitioner as an aspect of their new role. In a study on 'experiences of newly qualified midwives', Tarimo et al. (2018) concurred when they reported that, graduates expressed that they felt like they were just thrown at a deep end, as experienced midwives did not bother to offer any form of support.

The role of a registered midwife was accompanied by a very high level of responsibility and accountability which put more pressure on midwifery graduates. In an Irish study of 'newly qualified midwives', Van der Putten (2008) found that newly qualified midwives often struggled to adapt to their new role. These midwives explained that the increased responsibility and awareness of accountability, often led to feelings of fear and insecurity. This was supported by the findings of a study conducted by Hillman and Foster (2011) as well as Fenwick et al. (2012), who reported the increase responsibility and accountability as a major stressor in transition process. Hillman and Foster (2011) also described transition of graduates as moving between two different worlds; whereby, that of the student was sheltered, whereas the world of the newly qualified was exposed.

Wain (2017) revealed that, the expectation to take responsibility for overseeing junior students while consolidating their own training was difficult, especially when it occurred within the first month of employment. Asking very newly qualified midwives to take on this responsibility led to increased anxiety and frustration, which undermined their time for their own preceptorship and support. Stone (2018) reflected a similar view when reporting that there is nothing frustrating for a newly graduated midwife than being responsible for patients' care as well as students' learning at the same time. Chick and Meleis' Transition theory cited in Kumaran and Carney (2014) is also relevant in relation to midwifery graduates experiencing incongruence between former sets of expectations experienced during training; and those that prevail in the new situation as a midwifery graduate faced with a high level of responsibility and accountability as the cornerstone of midwifery practice. 


\section{Conclusion}

The study focussed on clinical practice of midwifery graduates during community service placement in Limpopo province, South Africa. Based on the findings, midwifery graduates felt exposed to two different worlds of midwifery practice; as they experienced the difference between theory and practice at different levels. The findings also revealed graduates' experience of reality shock resulting from loss of student's status accompanied by high level of responsibility and accountability. The study recommends that midwifery training programme should include opportunities to discuss the realities of the transition period, to enable graduates to deal with midwifery as well as management issues in a real and practical situation. There should be mentors in place to help graduates to bridge the gap between theory and practice. Structured support programmes should be offered to alley feelings of fear and insecurity resulting from increased levels of responsibility and accountability graduates are faced with.

\section{Acknowledgements}

The authors would like to thank the participants of the study.

\section{Competing Interests Statement}

The authors declare that there are no competing or potential conflicts of interest.

\section{References}

Adegoke, A. A., Atiyaye, F. B., Abubakar, A. S., Auta, A., \& Aboda, A. (2015). Job satisfaction and retention of midwives in rural Nigeria. Midwifery, 31, 946-956. https://doi.org/10.1016/j.midw.2015.06.010

Babbie, E. (2016). The practice of social research (14th ed.). Boston, B: Cengage.

Black, S. E. (2018). Does preceptorship support newly qualified midwives to become confident practitioners? British Journal of Midwifery, 26, 806-811. https://doi.org/10.12968/bjom.2018.26.12.806

Creswell, J. W. (2016). Research design. Qualitative, quantitative and mix methods approaches. Sage Publications Ltd: Thousand Oaks.

Cummins, A. M., Denney-Wilson, E., \& Homer, C. S. E. (2016). The mentoring experiences of new graduate midwives working in midwifery continuity of care models in Australia. Nurse Education in Practice, 12(2), $1-6$.

Dixon, L., Calvert, S., Tumilty, E., Kensington, M., Gray, E., Campbell, N., \& Pairman, S. (2015). Supporting New Zealand graduate midwives to stay in the profession: An evaluation of the Midwifery First Year of Practice programme. Midwifery, 12(4), 102-114. https://doi.org/10.1016/j.midw.2015.02.010

Duchscher, J. E. B. (2009). Transition shock: the initial stage of role adaptation for newly graduated Registered Nurses. Journal of Advanced Nursing, 65, 1103-1113. https://doi.org/10.1111/j.1365-2648.2008.04898.x

Fenwick, J., Hammond, A., Raymond, J., Smith, R., Gray, J., Foureur, M., Home, K., \& Symon, A. (2012). Surviving, not thriving: a qualitative study of newly qualified midwives' experience of their transition to practice. The Journal of Continuing Education in Nursing, 41, 2055-2068. https://doi.org/10.1111/j.1365-2702.2012.04090.x

Hillman, L., \& Foster, R. R. (2011). The impact of a nursing transitions programme on retention and cost savings. Journal of Nursing Management, 19(7), 50-56. https://doi.org/10.1111/j.1365-2834.2010.01187.x

Kensington, M., Campbell, N., Gray, E., Dixon, L., Tumilty, E., Pairman, S., Calvert, S., \& Lennox, S. (2016). New Zealand's Midwifery Profession: Embracing graduate midwives' transition to practice. New Zealand College of Midwives Journal, 52(4), 20-25. https://doi.org/10.12784/nzcomjn152.2016.3.20-25

Kumaran, S., \& Carney, M. (2014). Role transition from student nurse to staff nurse: Facilitating the transition period. Nurse Education in Practice, 14(3), 605-611. https://doi.org/10.1016/j.nepr.2014.06.002

Lennox, S., \& Foureur, M. (2012). Developmental mentoring: New graduates' confidence grows when their needs shape the relationship. New Zealand College of Midwives Journal, 46(11), 26-31.

Lewis, S., \& McGowan B. (2015). Newly qualified nurse's experiences of preceptorship. British Journal of Nurses, 24(1), 40-43. https://doi.org/10.12968/bjon.2015.24.1.40

Mason, J., \& Davies, S. (2013). A qualitative evaluation of a preceptorship programme to support newly qualified midwives. Journal of the Royal College of Midwives, 11(3), 94-98.

Power, A. (2015). Contemporary midwifery practice: art, science or both? British Journal of Midwifery, 23(9), 654-657. https://doi.org/10.12968/bjom.2015.23.9.654 
Power A. (2016). Midwifery in the 21st century: Are students prepared for the challenge? British Journal of Midwifery, 24(1), 66-68. https://doi.org/10.12968/bjom.2016.24.1.66

South Africa. (2005). Nursing Act (no 33 of 2005, as amended). Pretoria, P: Government Printer.

Stone, H. (2018). Does preceptorship support newly qualified midwives to become confident practitioners? British Journal of Midwifery, 26, 806-811. https://doi.org/10.12968/bjom.2018.26.12.806

Tarimo, E. A. M., Moyo, G., Masenga, H., Magesa, P., \& Mzava, D. (2018). Performance and self-perceived competencies of enrolled nurse/midwives: a mixed methods study from rural Tanzania. BMC Health Services Research, 18(4), 1-14. https://doi.org/10.1186/s12913-018-3096-8

Van der Putten, D. (2008). The lived experience of newly qualified midwives: A qualitative study. British Journal of Midwifery, 16(6), 348-359. https://doi.org/10.12968/bjom.2008.16.6.29592

Wain, A. (2017). Examining the lived experiences of newly qualified midwives during their preceptorship. British Journal of Midwifery, 25(7), 451-457. https://doi.org/10.12968/bjom.2017.25.7.451

\section{Copyrights}

Copyright for this article is retained by the author(s), with first publication rights granted to the journal.

This is an open-access article distributed under the terms and conditions of the Creative Commons Attribution license (http://creativecommons.org/licenses/by/4.0/). 